\title{
PROFESSIONAL SPORT AND MARKET RESTRICTIONS: IS THE PLAYER POINTS SYSTEM IN THE AUSTRALIAN NATIONAL BASKETBALL LEAGUE AN UNFAIR RESTRAINT OF TRADE?
}

\author{
JACOB HOLMES
}

This article analyses the Australian National Basketball League's 'Player Points System' to ascertain the real impact of the system on the sport, clubs and athletes. It argues that the system works against the best interests of the sport and is an unreasonable restraint on the trade of the athletes. Ultimately, this article calls for the Player Points System to be abandoned and replaced by a more effective system such as the Restricted Free Agency labour market restraint model that is used in the Australian Football League and American National Basketball Association. It concludes that this system could more adequately promote the best interests of the National Basketball League and the players without constituting an unreasonable restraint of trade.

I Introduction. 113

II Salary Caps 114

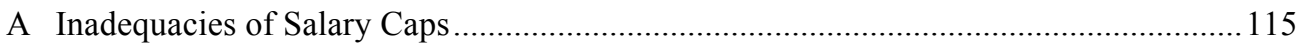

III

The Player Points System ....

A Operation of the PPS

B Merits of the PPS 118

1 Assist the Salary Cap

2 Restrict Strong Clubs

C Critique of the PPS: The Real Impact.

1 Loss of Clubs 119

2 Equality and Competitiveness

3 Other Negatives.

LLB student, Law School, University of South Australia; former player in the NBL (407 career games); Chief Officer of the Australian Basketballers' Association (formerly known as the NBL Players' Association); Deputy General Secretary, Australian Athletes' Alliance. 
4 Case Examples

D PPS and Restraint of Trade

A Restricted Free Agency

B Benefits of Restricted Free Agency

C Tailored to the Competition

\section{INTRODUCTION}

Systems that actively regulate the labour markets in professional sport operate across Australia and the world. One of the most popular is the salary cap. The salary cap is designed to regulate the sporting competition to ensure competitive equality and to maintain 'outcome uncertainty' by restricting all clubs to a maximum amount they can spend on their team. ${ }^{1}$ However, the inability of salary caps to adequately address the wants and needs of professional sports has led to the introduction of additional restrictions in several competitions ${ }^{2}$ as well as the use of advanced and expensive investigation units. ${ }^{3}$ This paper will explore one such 'adjunctive system', the Player Points System ('PPS') employed by the National Basketball League ('NBL'), in detail. Adjunctive systems are defended not only on the basis that salary caps by themselves are extremely difficult to police but also because club owners frequently demonstrate a disregard for salary cap limitations. ${ }^{4}$ Adjunctive systems, in conjunction with salary caps, are seen to better accommodate the need for equality between sporting clubs. However, any addition of adjunctive systems to the existing restriction of salary caps further impairs the workplace rights of athletes. ${ }^{5}$ Therefore, the implementation of these 'supportive' systems comes at a real cost to athletes' rights and

\footnotetext{
Antonio Buti, 'Salary Caps in Professional Team Sports: An Unreasonable Restraint of Trade' (1999) 14 Journal of Contract Law 130, 143.

2 See, eg, National Basketball League Player Points System (established 2004); Australian Football League ('AFL') Player Draft and Restricted Free Agency; National Rugby League Marquee Player rule (established 2010) and Long Service Player Allowance (established 2003); A-League Marquee Player rule (established 2005).

3 See, eg, AFL's 'Legal, Integrity and Compliance Department'.

4 Justin Cook and Chris Davies, 'Free Agency and the Australian Football League' (2012) 24 Bond Law Review 64, 66-67.
}

$5 \quad$ Ibid 68. 
wellbeing - and this cost can be justified only if it is outweighed by the overall benefit that the system provides to the league. ${ }^{6}$

Part II of this paper explores salary caps and their perceived inadequacies and explains the basis for implementing adjunctive restrictive systems in sports leagues. Part III considers the NBL's Player Points System and the merits behind its implementation before moving on to analyse and critique the system against its rationale and the doctrine that prohibits unreasonable restraints of trade. Part IV examines Restricted Free Agency as an alternative model that could be enacted in place of the PPS. The article concludes by recommending that the NBL should, at a minimum, replace the PPS with Restricted Free Agency as a more reasonable and less restrictive adjunct to the salary cap.

\section{SALARY CAPS}

Salary caps are the most popular form of restrictive tool used by professional sports in Australia: versions operate in the Australian Football League ('AFL'); National Rugby League ('NRL'); National Basketball League ('NBL'); A-League Football competition; ANZ Netball Championship; and Australian Super League Rugby Union ('ARU'). Sports leagues argue 'that they are in a unique industry' and justify the existence of salary caps on the basis that 'sporting equality' between clubs is essential to maintaining 'the economic prosperity of the entire league'. ${ }^{7}$ However, as Antonio Buti explains, these systems can be challenged:

Salary cap systems in Australian professional team sports leagues are vulnerable to a restraint of trade challenge. The legitimate interests of leagues and their constituent clubs do not make it reasonably necessary to impose artificial salary restraints on players. ${ }^{8}$

Salary caps have received inconsistent judicial commentary. In Adamson $v$ New South Wales Rugby League Ltd (No 2), Sheppard J stated:

The validity [of the salary cap] was assumed by all parties. I have no reason to think that the rules may be invalid - I have not considered them; but I would

$6 \quad$ Nordenfelt $v$ Maxim Nordenfelt Guns and Ammunition Co Ltd [1894] AC 535, 548-549 ('Nordenfelt'); Adamson v New South Wales Rugby League Ltd (1991) 31 FCR 242, 273 ('Adamson').

7 Buti, above n 1, 130.

8 Ibid 153. 
not wish to pre-empt the decision of this or any other court which may need in the future to deal with these rules. ${ }^{9}$

Nonetheless, action by the players has only ever been threatened, not acted upon, ${ }^{10}$ and the use of salary caps is generally accepted by the major professional codes and their players' associations. Moreover, the validity of salary caps in ensuring the competitive balance and stability of the leagues has been well defended. ${ }^{11}$ As mentioned above, the 'need' for competitive equality (or 'outcome uncertainty') and organisational sustainability have commonly been used to justify enacting salary caps and other restrictive measures. $^{12}$

\section{A Inadequacies of Salary Caps}

The most significant and publicly known problem with salary cap systems is the inability of professional leagues to police them. The recent breach of the A-League Salary Cap by the Perth Glory Club is not an isolated instance in Australia. ${ }^{13}$ Since the inception of salary cap use in professional sport, numerous high profile and highly damaging breaches of this marketplace restriction have been seen. The most high profile case is the NRL Melbourne Storm breach, which led to the revocation of two premiership titles from the years 2007 and 2009. This penalty was in addition to the loss of competition points and a monetary fine in excess of $\$ 1600000 .{ }^{14}$ There have been many other salary cap breaches in the NRL and the AFL since their inception. ${ }^{15}$ Notably, the cap breaches by the Carlton Blues (AFL) and Canterbury Bulldogs (NRL) were discovered by external third parties and not by the relevant sports investigation bodies. In the case of the Canterbury Bulldogs, it was a local journalist whose investigative work then provided the impetus to the Carlton Blues discovery. ${ }^{16}$ Thus, despite the intentions of salary cap

(1991) 31 FCR 242, 249

10 Cook and Davies, above n 4, 64-65.

11 See, eg, Chris Davies, 'The Use of Salary Caps in Professional Team Sport and the Restraint of Trade Doctrine’ (2006) 22 Journal of Contract Law 246, 266.

12 Buti, above $\mathrm{n} 1$.

13 Dominic Bossi, 'Perth Glory Fined \$269,000 and Booted Out of A-League Finals Series for Salary Cap Breaches' The Sydney Morning Herald (online), 10 April 2015 $<$ http://www.smh.com.au/sport/soccer/perth-glory-fined-269000-and-booted-out-of-aleaguefinals-series-for-salary-cap-breaches-20150410-1mifve.html>.

14 National Rugby League ('NRL'), 'Melbourne Storm Breach NRL Salary Cap' NRL Official Website (online), April $222010<\mathrm{http}$ //www.nrl.com/melbourne-storm-breach-nrl-salarycap/tabid/10874/newsid/58359/default.aspx>.

15 See, eg, Carlton Blues (AFL) and Canterbury Bulldogs (NRL) in 2002.

16 David Thorpe et al, Sports Law (Oxford University Press Australia, $2^{\text {nd }}$ ed, 2013) 416. 
designers, the caps themselves are extremely difficult to police even by wellresourced sporting codes. ${ }^{17}$

Consequently, all of the major professional leagues in Australia (AFL, NRL, A-League and NBL) have enacted supplementary systems to enable their salary caps to operate more effectively and to achieve their desired impact. ${ }^{18}$ Cook and Davies state that the 'main objective of the salary cap is to standardise the amount each club can allocate to player payments' but add that this needs to be supported by the 'draft (and restricted free agency system) to ensure a competitive balance throughout the league'. ${ }^{19}$ So, while salary caps are a useful tool to ensure standardised player payments, they do not by themselves solve the problems relating to the best interests of sporting competitions, namely 'competitive equality, financial viability and player retention. ${ }^{20}$ Moreover, too little consideration is given to the relatively short duration of professional athletes' careers and the impact that any period of unemployment or reduced income within this short term could have on the livelihoods of these athletes. Therefore, when analysing any adjunctive restrictive model that supplements the salary cap, it is important to take into account the impact that the extra restriction has on the overall best interests of the sport as well as the impact it has on the professionals who compete within that league.

\section{The Player Points System}

The inadequacies of salary caps have resulted in the implementation of further restrictions to serve as an adjunct to the salary cap. These systems include: player drafts and restricted free agency used in the AFL; 'marquee player' exemptions used in the A-League, NRL and NBL; and the Player Points System used in the NBL and the National Premier League Victoria football league. The PPS is one of the most contentious of these adjunctive systems. This is because it is a novel system that is not employed by any other professional sporting league in the world. ${ }^{21}$ The PPS has been

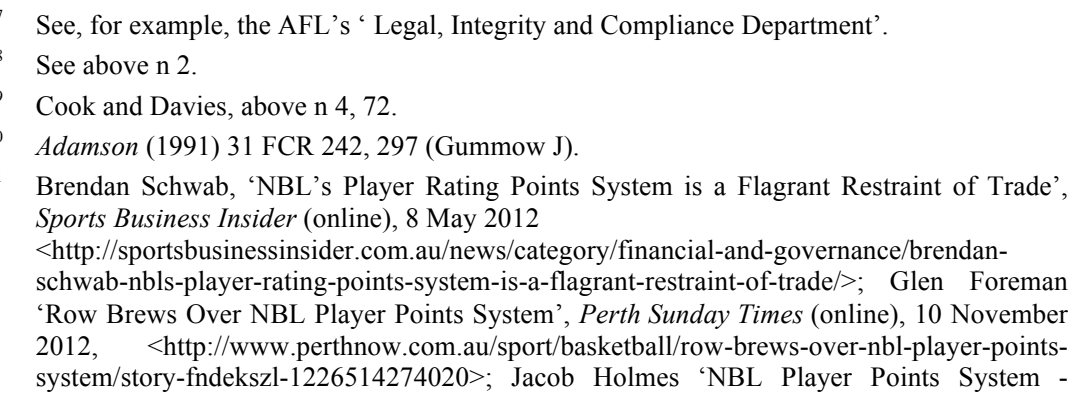


employed by the NBL since 2004. The NBL Rules and Regulations state that the 'rationale' behind the PPS is 'to ensure that all clubs have equitable access to the player talent in order to maximise the quality of the competition'.22

\section{A Operation of the $P P S^{23}$}

The PPS rates each player on a club's ten player roster with a value between 1 and 10 . The ' 10 point' players are the highest calibre player that the league can have and include 'import' players (such as ex-National Basketball Association ('NBA') players and other internationals) and international representative players (Australian Boomers in Olympics and World Cups). The ' 1 point' players are those who come straight out of the domestic competitions and are young or not rated very highly, as they have not competed in a professional league before. Notably, 'rookie' (first year) players are often given higher than a ' 1 point' rating. For example, graduates from the United States college system are given a ranking of no less than three points.

The PPS ratings are formulated by a mathematical equation which takes a set of different statistics from the players and gives them a number between 1 and 10. The second stage involves these player ratings being sent to the Points Appeal Panel. This panel was originally made up of a Chairman and two other representatives chosen by the NBL, and two representatives chosen by the NBL Players' Association ('NBLPA'). ${ }^{24}$ This group is tasked with the computer generated ratings and determining whether they are 'appropriate'. ${ }^{25}$

Once all the player ratings are completed, the clubs are required to fit their ten player rosters within a cap of 70 Total Player Points ('TPP'). The TPP, or total team allowance of points, effectively dictates that all teams must restrict themselves in their contracting to keep their team roster of ten players under 70 total points.

Release of Final Player Points Rankings', National Basketball League Players Association (online), 30 April $2014<$ http://www.nblpa.com.au>.

22 National Basketball League, Rules and Regulations s 6, cl 25.1

$<$ http://www.nblpa.com.au/uploads/1/9/7/2/19723749/nbl-rules-and-regulations-2011-12-

final.pdf $>$

23 The details in this section are personally known to the author.

24 The NBL Players' Association is now known as the Australian Basketballers' Association ('ABA').

25 The NBLPA (now ABA) has recently removed itself from the Points Appeal Panel due to the uneven representation on the Panel (three votes for the NBL and two for the NBLPA), and the unwillingness of the NBL to address the concerns of the players regarding the negative impacts and restrictions of the PPS. See, Holmes, above $n 21$. 


\section{B Merits of the PPS}

The rationale behind the NBL's enactment of the PPS can be condensed to two key points: the first goal is to assist the salary cap, given the difficulties with policing; and the second is to restrict strong clubs by reducing their ability to 'stack' teams with high calibre players. ${ }^{26}$

\section{Assist the Salary Cap}

The NBL is not alone in being unable to police their salary cap adequately. As outlined above, the salary cap is extremely difficult to regulate even in sports with vastly more resources than the NBL and dedicated salary cap investigators. ${ }^{27}$ Moreover, the inclusion of third-party agreements, player sponsorships, player speaking engagements and family employment all make salary caps easy to evade and difficult to police.

In addition, the exceptional instability within the NBL from both a league and club perspective makes it even more difficult for the NBL to police and enforce their salary cap. ${ }^{28}$ Any financial or competition-based penalty that the NBL might impose on a club for a salary cap breach could cause the collapse of the club, which in turn could cause the collapse of the league. The NBL has only 8 teams and the loss of one team, due to their inability to pay a fine or because of the negative commercial effects of a loss of competition points, could cause the entire league to close down. This places the NBL in an extremely vulnerable position, and so to minimise this risk of collapse, the NBL has opted to implement a dual system that supplements the salary cap with an adjunctive PPS.

\section{Restrict Strong Clubs}

There is vast economic inequality between clubs in the NBL competition. ${ }^{29}$ Without the PPS, the best resourced teams would be able to 'stack' their

26 National Basketball League Official Website, Salary Cap/Player Points: $<$ http://www.nbl.com.au/salary-cap-player-points $>$.

27 See above $n 3$.

28 See Paul Suttor, 'NBL Can't Afford to Shut Down to Fix Woes But Six-Team Format a No Go Zone', The Sydney Morning Herald (online), 12 March 2015 $<$ http://www.smh.com.au/sport/basketball/nbl-cant-afford-to-shut-down-to-fix-woes-butsixteam-format-a-nogo-zone-20150312-142r0g.html>.

29 While official financial data is not provided by NBL clubs, the recent voluntary administration of the Wollongong Hawks and Townsville Crocodiles when compared with the Perth Wildcats \$1million profit provides strong evidence. See John Stensholt 'Wildcats: a Slam Dunk for Jack Bendat at 89', The Australian Financial Review (online), 31 March $2014<$ http://www.afr.com/business/wildcats-a-slam-dunk-for-jack-bendat-at-89-20140330ix $9 \mathrm{t} 3>$. 
teams with high calibre players. The implementation of the PPS ensures that the most affluent clubs cannot obtain all the best available players, because no matter how much money is spent, clubs are still allowed only 70 points 'worth' of players. Therefore, they cannot contract ten 10 point players, and must make adjustments in their recruitment to adhere to the 70 point total team maximum.

\section{Critique of the PPS: The Real Impact}

Ultimately, the aim of the PPS is to preserve the best interests of the NBL. However, in order to evaluate the efficacy of the system, it is imperative that the practical impact of the system is explored. Furthermore, the system must not constitute an unreasonable restraint of trade on NBL players. This section provides a critique of the PPS and considers the real impact that the system has had on the NBL (and its best interests) and the players (and their rights to freedom of movement and trade) ten years after its inception.

\section{Loss of Clubs}

Since the introduction of the PPS in 2004, the NBL has had seven teams enter into liquidation or be dissolved (Hunter Pirates, Singapore Slingers, Victoria Giants, South Dragons, Brisbane Bullets, Sydney Spirit, Gold Coast Blaze). In addition, the Townsville Crocodiles, Adelaide 36ers, Wollongong Hawks and Sydney Kings have all either entered voluntary administration and/or been shut down temporarily before changing their management teams during this ten year period. The number of teams competing in the NBL at the initiation of the PPS was twelve. This number now stands at eight. This means there has been a 33 per cent reduction in the number of teams in the NBL competition in a decade.

Not all the blame for the state of the NBL competition can be attributed to the introduction of the PPS. Poor club and league management, lack of commercial and broadcast partners, increased commercialisation and promotion of rival codes, and a myriad of other issues are all likely contributing factors. ${ }^{30}$ Nonetheless, and despite the intentions of the PPS to ensure club viability, there has never been a greater period of instability in the NBL's history. In fact, in the ten years since the PPS was established by the NBL, the league has lost more clubs than in the previous twenty years since the league was formed. Furthermore, the NBL has merged and demerged from the governing body, Basketball Australia, within this same

30 See Nick Smart 'Andrew Gaze Calls for 'Broken' NBL to be Shut Down', Herald Sun (online), 11 March $2015<\mathrm{http}$ //www.heraldsun.com.au/sport/basketball/andrew-gaze-callsfor-broken-nbl-to-be-shut-down>. 
period. It can be reasonably argued that the sustainability and viability of the NBL has worsened since the enactment of the PPS.

\section{Equality and Competitiveness}

The aim for competitive balance is a common goal of professional sporting leagues. ${ }^{31}$ In theory this equality provides a more attractive spectacle because the results of each game and each season are less predictable and 'outcome uncertainty' is maintained. ${ }^{32}$ To demonstrate the inequality of the NBL competition, Table 1 displays data showing the average table positions of the eight current clubs. It provides the 'Average Table Position' which is based on the number of seasons that a club has been in the NBL and the annual table position in each of those seasons. If the NBL competition was well balanced the 'Average Table Position' of all clubs should be between 5-6. ${ }^{33}$

Table 1 (Sourced from the NBLPA, April 2014.)

\begin{tabular}{|l|l|}
\hline NBL Team & Average Table Position \\
Perth Wildcats & 3.63 \\
\hline Sydney Kings & 4.13 \\
\hline New Zealand Breakers & 5.77 \\
\hline Adelaide 36ers & 5.80 \\
\hline Wollongong Hawks & 5.96 \\
\hline Townsville Crocodiles & 6.33 \\
\hline Cairns Taipans & 6.71 \\
\hline
\end{tabular}

31 Buti, above n 1, 142

32 Ibid.

33 This would take into account the increased number of teams during certain periods of the NBL, which was 13 at its maximum. 
Table 1 demonstrates that, despite the best intentions behind the PPS, inequality remains a feature of the competition. There is a notable consistency of ladder positions in the NBL which means that the top teams consistently remain at or near the top, and the bottom teams consistently remain at or near the bottom. Notably, the New Zealand Breakers team entered the NBL only in 2003, and since that time, it has won four of the past five championships. In fact, in the past six seasons, either Perth or New Zealand has won the NBL Championship. There is, therefore, a lack of competitive equality or outcome uncertainty in the NBL — and it can be safely concluded that the PPS has resulted in greater inequality between the teams.

\section{Other Negatives}

The construction of the PPS dictates that a player's value to the NBL competition, and to any club within it, is determined only by a player's statistics. Therefore, a player's individual circumstances are irrelevant. For example, a player's PPS rating may preclude them from moving to their hometown club for family or personal reasons. Equally, where a player is rated as a '7 point' player and a club has only six points to spare in their total team allowance, the player will be unable to sign with the team. This outcome fails to take into account any willingness that a player may have to accept a lower salary or a lesser position in the team. Consequently, the system determines where a player can play without any consideration of that player's economic position, personal circumstances, club loyalty or league tenure.

In 2013/14 the NBL enacted the 'Loyalty Discount' rule which reduces a player's point rating if they have played at a club for longer than five years (2 point reduction) and 10 years (4 point reduction). ${ }^{34}$ However, this rule has had a negative impact on the players, because it acts as a further restriction. This is because the points reduction applies only for the player's current team; it is not applied if the player moves clubs. For example, where a player moves to another club, their player points rating would be higher (ie, increased to pre-loyalty discount value) compared to the rating they would have had if they had stayed at their existing club. As a result, the rule does not provide a benefit to a player unless they want to remain at their existing club.

Another negative effect of the PPS can be experienced when a player has a 'break-out' season that substantially increases their statistical output. In these

34 National Basketball League Official Website, above n 26. 
instances, a player's rating will increase, sometimes by up to four points. ${ }^{35}$ This effectively penalises a player for exceptional performance because it makes it more difficult for the player to be employed (due to the team's 70 allowable points total). This was the case for many players of the Perth Wildcats recently. The Perth Wildcats, having won the NBL Championship in the 2013/14 season, were forced to make team roster changes as a result of the increases in individual player points ratings and their consequent inability to keep all their existing players under the team's total allowable points.

It is also worth mentioning the effect that the PPS has on player recruitment and retention. While an athlete's abilities ought to be the primary focus of team selection processes, the PPS dictates that the most important discourse in a club centres around the point value of each player and whether this number will fit within their 70 point team allowance. This means that a player's worth is not determined by their ability and/or cost; instead it is based on their point rating, something which is outside the player's control or influence.

4 Case Examples ${ }^{36}$

\section{(a) Mick Hill}

Mick Hill was a seven year veteran in the NBL when his two year contract was terminated mid-term due to the collapse of the Championship winning Brisbane Bullets club. As a result of Mick's ' 7 point' player rating, and despite his willingness to accept a lower salary and move cities to continue to be employed, he was unable to secure a contract with another team. His high points rating made him an unattainable prospect due to his team's total allowable point restrictions. No adjustments were made by the NBL. Mick never played another NBL game and his career was over at 29 years of age.

\section{(b) Tom Daly}

Tom Daly was 22 years old when he played with the Adelaide 36ers. Tom was a 'development' player, so he was permitted to train with the team, but was not permitted to play. In 2013 Tom was elevated to the playing roster late in the season and subsequently played 17 games for the team. Despite being a development player and having played very limited court time, Tom's rating was elevated to ' 3 points'. He was offered two contracts if he

35 See Tom Jervis 2013/14-2014/15 from 3 to 7; Jeremiah Truman in 2012/13-2013/14 from 2 to 6 .

36 The details in this section are personally known to the author. 
could get down to a '2 point' player, but his appeals to the NBL were rejected. Tom was not employed in the following NBL season $(2013 / 14)$.

\section{(c) Jeremiah Truman}

The PPS effectively penalised Jeremiah Truman of the Perth Wildcats for being a high-achieving player. Jeremiah had a break-out season in 2012/13 which saw his rating rise from ' 2 points' to ' 6 points'. However, as a result of the increase in Jeremiah's point rating, and the inability of his team to accommodate this increase in his team's total points allowance without cutting other players, Jeremiah was released from his team. The PPS affected Jeremiah in a very negative way.

\section{PPS and Restraint of Trade}

The analysis of the PPS demonstrates that the system has had a dramatic impact not only on the NBL competition but also on the players' livelihoods and their freedom to pursue their trade. However, this in itself is not enough to label the PPS as an unfair and unreasonable restraint of trade. In the case of Nordenfelt $v$ Maxim Nordenfelt Guns and Ammunition Co Ltd, ${ }^{37}$ which was applied in a sports context in Adamson $v$ New South Wales Rugby League Ltd, ${ }^{38}$ Lord Macnaghten explained that as a general rule, '[a]11 interference with individual liberty of action in trading, and all restraints of trade themselves, if there is nothing more, are contrary to public policy and therefore void'. ${ }^{39}$ However, his Lordship went on to explain that a restraint of trade 'can be justified by the special circumstances of a particular case': ${ }^{40}$

It is sufficient justification, and indeed it is the only justification, if the restriction is reasonable - reasonable, that is, in reference to the interests of the parties concerned and reasonable in reference to the interests of the public, so framed, and so guarded as to afford adequate protection to the party in whose favour it is imposed, while at the same time it is in no way injurious to the public.

So, as Thorpe et al explain, the test requires consideration of three key questions: ${ }^{41}$

1. Is the restraint reasonably necessary to protect the legitimate objectives of the league?

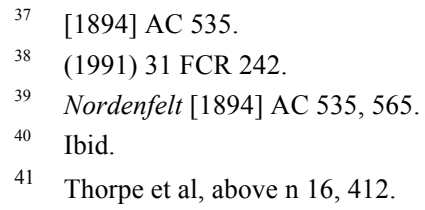


2. Is the restraint reasonable as far as the players' interests are concerned?

3. Is the restraint injurious to the public interest?

While the intentions or 'rationale' of the PPS may be valid and defensible, the real question is: what impact does the system have on the league, players and public? To answer this question, the PPS must be assessed under the 'Nordenfelt' criteria.

1 Is the PPS reasonably necessary to protect the legitimate objectives of the $N B L$ ?

Since the introduction of the PPS, the NBL has lost more teams than in any other period of the competition. Moreover, there is greater club inequality in terms of the ladder position. Success on the part of the club or player is effectively penalised. Therefore, it is clear that the PPS works counterproductively to the best interests and objectives of the NBL.

\section{Is the PPS reasonable as far as the players' interests are concerned?}

The players are rated without reference to personal interests and personal circumstances. Furthermore, players are penalised for good performance and severely restricted in their movement between clubs as a result of total team allowance points. These factors strengthen the argument that the PPS is unreasonable as far as players' interests are concerned.

\section{Is the PPS injurious to the public interest?}

The public is injured because the PPS restricts the NBL in obtaining and/or retaining the best possible talent. This is because the key criterion for clubs is remaining under the 70 point allowance rather than their financial capacity or a player's sporting prowess. The PPS restriction denies the prospect of growth because the total team allowance of 70 points has never been raised, despite the loss of four teams since it was introduced. Thus, 40 players have been made unemployable without any compensation or adjustment to the PPS's total team allowance. Indeed, outstanding players have been denied access to the best league in the Australasian region as a result of the PPS restrictions.

The application of these three key tests suggests that the PPS constitutes an unreasonable and unjustified restraint of trade. 


\section{An Alternative Model}

In Adamson the Federal Court of Appeal held that, in instances where a restraint of trade is in dispute, an administrator may be required to demonstrate that a less restrictive alternative is unavailable. ${ }^{42}$ This section explores an alternative adjunctive system which could better assist the NBL in ensuring that, to adopt the words of the NBL Rules and Regulations, 'all clubs have equitable access to the player talent in order to maximise the quality of the competition. ${ }^{43}$ There are many adjunctive systems around the world that have been enacted by the various leagues and this section focuses on the 'Restricted Free Agency' system, which is employed in the United States by the National Basketball Association ('NBA'), the biggest basketball league in the world. This system has also recently been implemented in the AFL, the biggest sports league in Australia. The Restricted Free Agency system has received support as the 'best possible model for free agency' and has been hailed as one that 'attempts to find a balance between the AFL's legitimate interest in protecting the competitive balance of the competition, and the players' desire for greater employment mobility'. ${ }^{44}$

\section{A Restricted Free Agency ${ }^{45}$}

In 2012 the AFL enacted the free agency system to enable the transfer of players between clubs. In basic terms, the AFL system provides that 'restricted players' are those players who are in the top 25 per cent of a club's highest paid players (and who are restricted for 10 seasons), while all others are restricted for their first eight seasons (unless delisted or cut by their club). The restriction comes into effect when a restricted player ends a contract with their existing club. The existing club has the 'last right of refusal', which means they can match (or better) any offer that another club makes when trying to recruit the player.

If the existing club matches the offer, the player must either remain at their existing club or enter the draft where they could be employed by any club who then selects them. If the existing club does not match the offer, the player may move and take the higher offer elsewhere. If a player moves to a new club or enters the draft, the previous club will receive compensation for their loss. Where a player is not in the top 25 per cent of player payments for a team, and has played over eight years with one club (or is cut by a club),

42 Adamson (1991) 31 FCR 242, 370-2 (Gummow J).

43 See above $\mathrm{n} 22$.

44 Cook and Davies, above n 4, 100.

45 AFL, Free Agency Rules (2012) <www.afl.com.au/afl-hq/the-afl-explained/free-agency>. 
they are then deemed to be an unrestricted 'free agent' and can sign with any team without restriction. The use of this system alongside the salary cap reduces the pressure on the salary cap.

\section{B Benefits of Restricted Free Agency}

The Restricted Free Agency system imposes a much less onerous restriction when compared with the PPS. While the Restricted Free Agency system restricts a player's movement and choice of team, it also ensures that all solicited players are employed in the league and paid market value. Therefore, notwithstanding that it restricts the movement of players to their preferred team to some degree, Restricted Free Agency ensures that players are restricted in the league for full market value, not pushed out of the league altogether.

The PPS, on the other hand, restricts a player not only in terms of movement but also in terms of financial capacity; and furthermore, it limits the available job market. The PPS restrictions push players out of the league if they are rated too highly or cannot be fitted into a team's total allowable points. This comparison suggests that the PPS constitutes an unfair restriction. Under the test applied in Adamson, which requires no 'greater restraint than is necessary for the adequate protection of the interests of the League and its members ${ }^{46}$ it appears that the PPS should be abandoned and be replaced by a Restricted Free Agency system.

\section{Tailored to the Competition}

The implementation of the Restricted Free Agency system by the AFL was based on consultation and negotiation between the AFL and AFL Players' Association ('AFLPA'). ${ }^{47}$ The focus of this process was 'on producing a system uniquely structured to suit the culture and traditions of the Australian competition, while acknowledging the rights of the players to increased selfdetermination of their playing careers'. ${ }^{48}$ Furthermore, the system was 'intended to protect the competitive balance of the competition while addressing player concerns on mobility, ${ }^{49}$ In summary, the interests of the

46 Adamson (1991) 31 FCR 242, 372 (Gummow J).

47 Caroline Wilson, 'AFL Justifiably Wary of Free Agency', The Age (online), 6 December $2009<$ http://www.theage.com.au/afl/afl-news/afl-justifiably-wary-of-free-agency20091205-kc3a.html>; cited in Cook and Davies, above n 4, 87.

48 Jennifer Witham, 'Free Agency for 2012', AFL Official Website, 23 September 2010, $<$ http://www.afl.com.au/tabid/208/default.aspx?newsid=89810>; cited in Cook and Davies, above $n$ 4, 89.

49 Will Brodie, 'AFL Clubs can Fight to Keep Stars Under Free Agency', The Age (online), 23 January $2010<$ http://www.theage.com.au/afl/afl-news/afl-clubs-can-fight-to-keep-stars- 
players and the league were paramount in designing the AFL's restricted free agency. This collaborative approach ensures the validity and efficacy of the system and provides a model for the NBL to implement in consultation with the players and their representative body, the Australian Basketballers' Association.

\section{CONCLUSION}

The salary cap, by itself, is arduous to enforce without full time salary cap investigators and contractual transparency. Even with these factors in place, there are still serious doubts over the ability of professional sporting leagues to police salary caps or even to deter any breaches. ${ }^{50}$ As a result, adjunctive restrictions are enacted in all major professional competitions.

Unlike the AFL or the NRL, the NBL does not have the financial resources to police the salary cap. The PPS is the league's attempt to use an adjunctive system to assist with the legitimate objectives of the competition. This article has demonstrated that, despite the best intentions of the PPS, it does not serve the best interests of the league, the clubs, the players or the public. Moreover, the system fails the restraint of trade test laid out in Nordenfelt ${ }^{51}$ and Adamson. $^{52}$

Consequently, in light of the counterproductive impact of the PPS, the NBL should abandon the PPS and employ an alternative adjunctive system. The Restricted Free Agency scheme is recommended as an alternative system worthy of the NBL's investigation. It has been successfully utilised by the NBA, the premier basketball league in the world, and by the biggest sports code in Australia, the AFL. To this end, it is recommended that the NBL engage in consultation talks with the Australian Basketballers' Association. Proactive collaboration would facilitate the drafting of an effective system, specifically tailored to support the best interests of players and the National Basketball League.

under-free-agency-20100223-ozy7.html>; Greg Denham, 'Free Agency Becomes a Reality', The Australian (online), 24 February $2010<\mathrm{http} / /$ www.theaustralian.com.au/ news/sport/free-agency-becomes-a-reality/story-e6frg7mf-1225833630075>; cited in Cook and Davies, above n 4,89 .

50 Buti, above $\mathrm{n} 1$.

$51 \quad$ [1894] AC 535.

52 (1991) 31 FCR 242. 
UPDATE: Since this article was written, the National Basketball League has undergone a change of management. It is now engaged in consultation with the players' representative body, the Australian Basketballers' Association, to enact a new Salary System for the National Basketball League competition. 